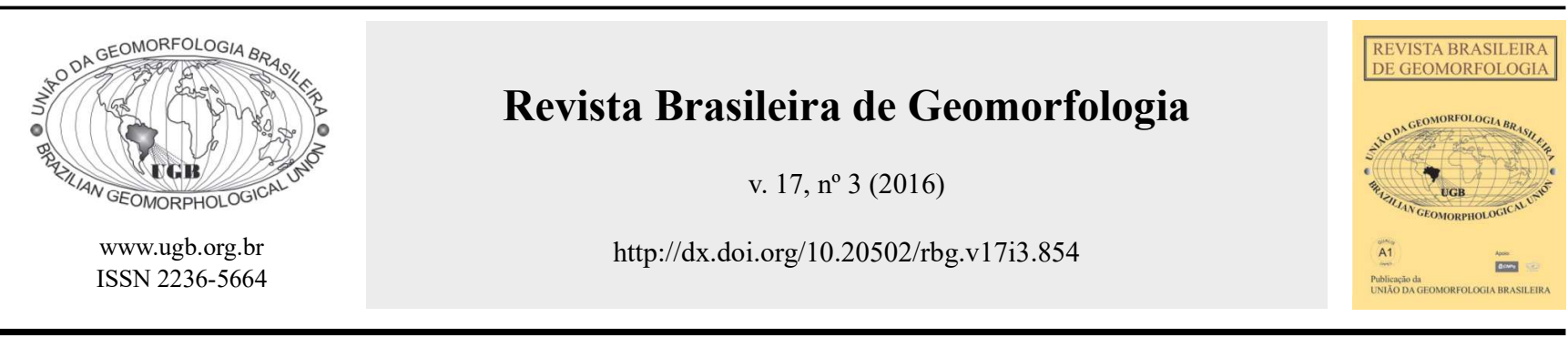

\title{
DETERMINAÇÃO DA EROSÃO COSTEIRA NO ESTADO DE PERNAMBUCO ATRAVÉS DE GEOINDICADORES
}

\section{COASTAL EROSION ESTIMATION BY THE USE OF GEOINDICATORS ALONG THE PERNAMBUCO STATE COASTLINE}

\author{
Karoline Angélica Martins \\ Departamento de Oceanografia, Universidade Federal de Pernambuco \\ Av. Arquitetura, s/n, Recife, Pernambuco, CEP: 50740-550, Brasil
}

Email:karol.martins@msn.com

Pedro de Souza Pereira

Departamento de Oceanografia, Universidade Federal de Pernambuco Av. Arquitetura, s/n, Recife, Pernambuco, CEP: 50740-550, Brasil Email: pedro.pereira@pq.cnpq.br

Anderson Pereira Lino

Departamento de Oceanografia, Universidade Federal de Pernambuco Av. Arquitetura, s/n, Recife, Pernambuco, CEP: 50740-550, Brasil

Email:aplino@live.com

Rodrigo Mikosz Gonçalves

Departamento de Engenharia Cartográfica, Universidade Federal de Pernambuco Av. Acadêmico Hélio Ramos, s/n, Recife, Pernambuco, CEP: 50740-530, Brasil

Email: rodrigo.mikosz@ufpe.br

\begin{tabular}{l} 
Informações sobre o Artigo \\
\hline Recebido (Received): \\
14/09/2015 \\
Aceito (Accepted): \\
15/05/2016
\end{tabular}

Palavras-chave:

Gestão Costeira; Obra de Proteção Costeira; Variação da Linha de Costa.

\section{Keywords:}

Coastal Management; Coastal Protection; Shoreline Change.

\section{Resumo:}

Processos erosivos podem ser identificados por meio de geoindicadores. O presente estudo classificou geoindicadores decorrentes da erosão no litoral de Pernambuco, no nordeste brasileiro. A metodologia foi baseada na detecção em campo da presença ou ausência de dez indicadores de erosão previamente descritos na literatura como recorrentes no litoral brasileiro. Estes indicadores foram agrupados em 4 classes de intensidade, sendo: nula (sem geoindicadores), baixa (geoindicadores ecológicos que não alteram significativamente a paisagem), moderada (geoindicadores morfológicos que alteram significativamente a paisagem) e alta (geoindicadores causados pela ação antrópica). Os principais geoindicadores observados foram: pós-praia estreito ou inexistente, escarpa erosiva nas dunas, obras estruturais de proteção costeira, e árvores na face de praia ou com raízes expostas. Ao longo dos $172 \mathrm{~km}$ de praias arenosas do estado de Pernambuco foi identificado que $48 \%$ não apresentaram nenhum geoindicador de erosão, $8 \%$ apresentaram geoindicadores de baixa intensidade, $16 \%$ de moderada intensidade e os demais $28 \%$ apresentaram geoindicadores de alta intensidade de 
erosão. Esses resultados foram comparados com a variação da linha de costa entre os anos de 2005 e 2014, obtida por meio de análise de imagens de satélite e em trabalho de campo, respectivamente. Uma análise estatística entre a presença de geoindicadores de erosão e as taxas de variação da linha de costa, mostra que não há boa correlação entre as duas variáveis. Por isso concluiu-se que os geoindicadores observados podem ser decorrentes de eventos erosivos anteriores ao período analisado, ou em virtude de alterações antrópicas no sistema, como o avanço da urbanização em direção ao mar e não necessariamente a um processo erosivo.

\section{Abstract:}

Erosional processes can be identified by geoindicators. This study ranked the intensity of erosion geoindicators on the coast of Pernambuco, in northeastern Brazil. The methodology is based on the field detection of the presence or absence of ten erosion indicators previously described in the literature as recurring on the Brazilian coast. These geoindicators were grouped into four intensity classes, as follows: zero (without erosion), low (ecological geoindicators that do not significantly modify the landscape), moderate (morphological geoindicators that significantly change the landscape) and high (geoindicators caused by human interaction). The main geoindicators observed were narrow or non-existent post-beach, erosive escarps in the dunes, coastal structures for protection, and trees on the beach face or with exposed roots. Throughout the $172 \mathrm{~km}$ of Pernambuco sandy beaches $48 \%$ shows no erosion impact, $8 \%$ had a low intensity of erosion, $16 \%$ had moderate intensity and the remaining $28 \%$ showed high intensity of erosion geoindicators. These results were compared with the shoreline change between the years 2005 and 2014, obtained from satellite images analysis and fieldwork survey, respectively. A statistical analysis of the erosion geoindicators and the coastline retreat rates showed that there is not a good correlation between the two variables. Therefore, it was concluded that the observed geoindicators on the beaches might result from erosive events prior to 2005, or due to anthropogenic changes on the system, such as the displacement of urbanization toward the sea.

\section{Introdução}

A erosão costeira é causada por alterações morfológicas no ambiente que acontecem como resultado de interações entre o ambiente praial e ondas, ventos, correntes, variações do nível do mar e processos antrópicos (NICOLODI, 2008; PRASETYA, 2007).

Ao longo de todo o litoral brasileiro foram relatados problemas decorrentes de processos erosivos (MUEHE, 2006). Dentre estes problemas estão a perda ou redução de áreas emersas com valor cultural e econômico, danos diretos ao patrimônio, depreciação da área para o setor turístico e urbanístico, além de gastos, públicos e privados com obras de proteção costeira.

O uso de geoindicadores foi apontado por Bush et al. (1999) como sendo uma alternativa para realizar avaliações do potencial risco de desastres naturais em áreas costeiras. Tais indicadores fornecem tendências que ajudam entender os processos atuantes na costa e, consequentemente, os perigos aos quais a mesma está sujeita. Os geoindicadores podem ser características gerais como a elevação e o tipo de vegetação, e também características especificas como a estabilidade e configuração da linha de costa (LC), a geomorfologia, o tipo de duna e de solo, por exemplo. O presente artigo utiliza alguns indicadores apresentados por Souza (2009) para avaliar a erosão existente nas praias arenosas do litoral de Pernambuco.

Um estudo anterior com base na presença de geoindicadores, em pontos estratégicos do litoral pernambucano, apontou que $33 \%$ das praias do estado estavam em erosão no momento do estudo (MANSO et al., 2006). A fim de incrementar e atualizar os dados existentes para o litoral pernambucano o presente artigo mostra uma classificação da intensidade dos geoindicadores de erosão ao longo do litoral do estado e compara esses dados com a taxa de variação da LC entre os anos de 2005 e 2014.

\section{Área de Estudo}

O estado de Pernambuco está localizado na região nordeste do Brasil, cuja capital é Recife, um dos 13 municípios que compõe o litoral do estado (Figura 1). A zona costeira de Pernambuco concentra $56 \%$ da população do estado, além das principais atividades econômicas, industriais, de recreação e turismo, que segundo o Ministério do Turismo (2014) tem grande importância econômica para a receita do estado. 

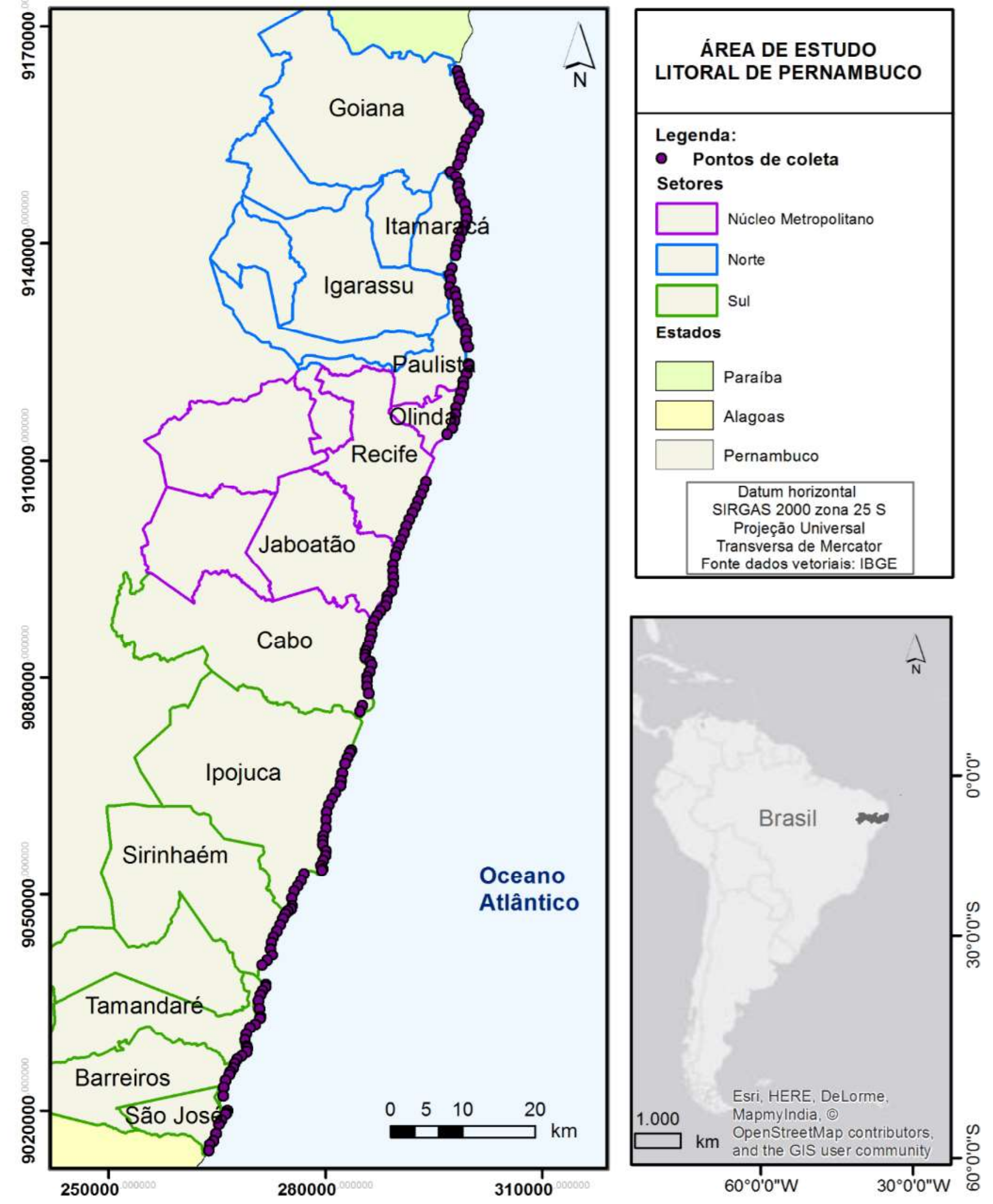

Figura 1 - Localização da área de estudo e dos 174 pontos de coleta. 
O litoral pernambucano se estende por $187 \mathrm{~km}$ com predominância de praias arenosas que compreendem os $172 \mathrm{~km}$ avaliados neste artigo. Uma característica morfológica típica ao longo deste trecho do litoral brasileiro são os arenitos de praia (beachrocks) paralelos à costa formados no período Holoceno (FERREIRA JÚNIOR et al., 2011). Os arenitos formam uma paisagem única, permitindo o desenvolvimento de recifes de corais sobre a rocha; que têm uma importância significativa para o turismo e para a proteção da zona costeira (DOMINGUEZ et al., 1990).

\section{Material e Métodos}

\section{Geoindicadores de erosão}

Os geoindicadores de erosão analisados foram baseados no estudo de Souza (2009) que descreveu os principais indicadores de erosão encontrados no litoral de São Paulo e concluiu que estes são também os mais comumente encontrados ao longo de todo o litoral brasileiro.

Dez geoindicadores foram analisados e agrupados em quatro classes que definem a intensidade da erosão costeira como está descrito abaixo:

- Intensidade Nula: praias que não possuem nenhum dos geoindicadores analisados;

- Intensidade Baixa: praias com a presença dos indicadores: I - vegetação rasteira de duna ou restinga soterradas ou com raízes expostas; II - escarpa erosiva nas dunas; e III - concentrações de minerais pesados na face da praia;

- Intensidade Moderada: praias com a presença dos indicadores: IV - árvores na face de praia ou com raízes expostas; V- marcas de erosão na base de muros residenciais; VI - pós-praia estreito ou inexistente; e VII - obras não estruturais de proteção costeira, pode apresentar ou não os indicadores do grupo de baixa intensidade;

- Intensidade Alta: praias com a presença dos indicadores: VIII - obras estruturais de proteção costeira; IX - infraestrutura da orla danificada por processos erosivos; e X - restos de construção na face de praia, pode apresentar ou não os indicadores dos demais grupos (Figura 2).

Os indicadores foram coletados a partir da observação em campo ao longo $187 \mathrm{~km}$ do litoral de Pernambuco, contabilizando 174 pontos de coleta ao longo do litoral distantes cerca de $1 \mathrm{~km}$ entre si (Figura 1). Posteriormente, os dados coletados de forma pontual foram extrapolados lateralmente formando 174 segmentos de forma que a integração desses compusesse a totalidade da LC do estado.

Para avaliar a significância relativa entre os geoindicadores, esses parâmetros foram correlacionados por meio do teste de componentes principais no software Bioestat ${ }^{\circledR}$. Os resultados foram dispostos em ordem decrescente de importância através de índices. De acordo com as especificações do teste somente resultados acima de $80 \%$ representam correlação significativa entre as variáveis.

Os resultados da classificação da intensidade dos geoindicadores são apresentados em relação aos três setores da zona costeira, segundo a definição do Plano Nacional do Gerenciamento Costeiro (BRASIL, 2004), sendo cada um deles composto pelos seguintes municípios:

- Setor Norte: Goiana, Itapissuma, Itamaracá, Igarassu, e Paulista;

- Núcleo Metropolitano: Recife, Olinda, Jaboatão dos Guararapes;

- Setor Sul: Cabo de Santo Agostinho, Ipojuca, Sirinhaém, Tamandaré, Barreiros e São José da Coroa Grande (Figura 1).

\section{Variação da linha de costa}

A variação da LC foi estabelecida através da diferença entre a LC de 2005 vetorizada sobre imagens de satélite e a LC de 2014 delimitada em campo. O propósito desta análise foi relacionar a presença de geoindicadores de erosão com taxas de retrogradação da LC. Para tal finalidade o erro decorrente da comparação de dados provenientes de diferentes metodologias, foi considerado aceitável pelos autores.

A LC de 2005 foi determinada sobre uma composição de 42 imagens RGB adquiridas pelo satélite IKONOS em 2005, com resolução espacial de $1 \mathrm{~m}$. Todas as imagens foram georreferenciadas em coordenadas UTM e datum SIRGAS 2000 zona 25S, as mesmas foram sobrepostas formando um mosaico da zona costeira de Pernambuco. A vetorização da LC sobre as imagens de satélite foi realizada no software ArcGis ${ }^{\circledR}$ baseando-se na evidência da linha de preamar máxima, por meio da delimitação entre o terreno seco e úmido. Na ausência desta evidência foi utilizada a primeira linha de vegetação como delimitação da LC. 

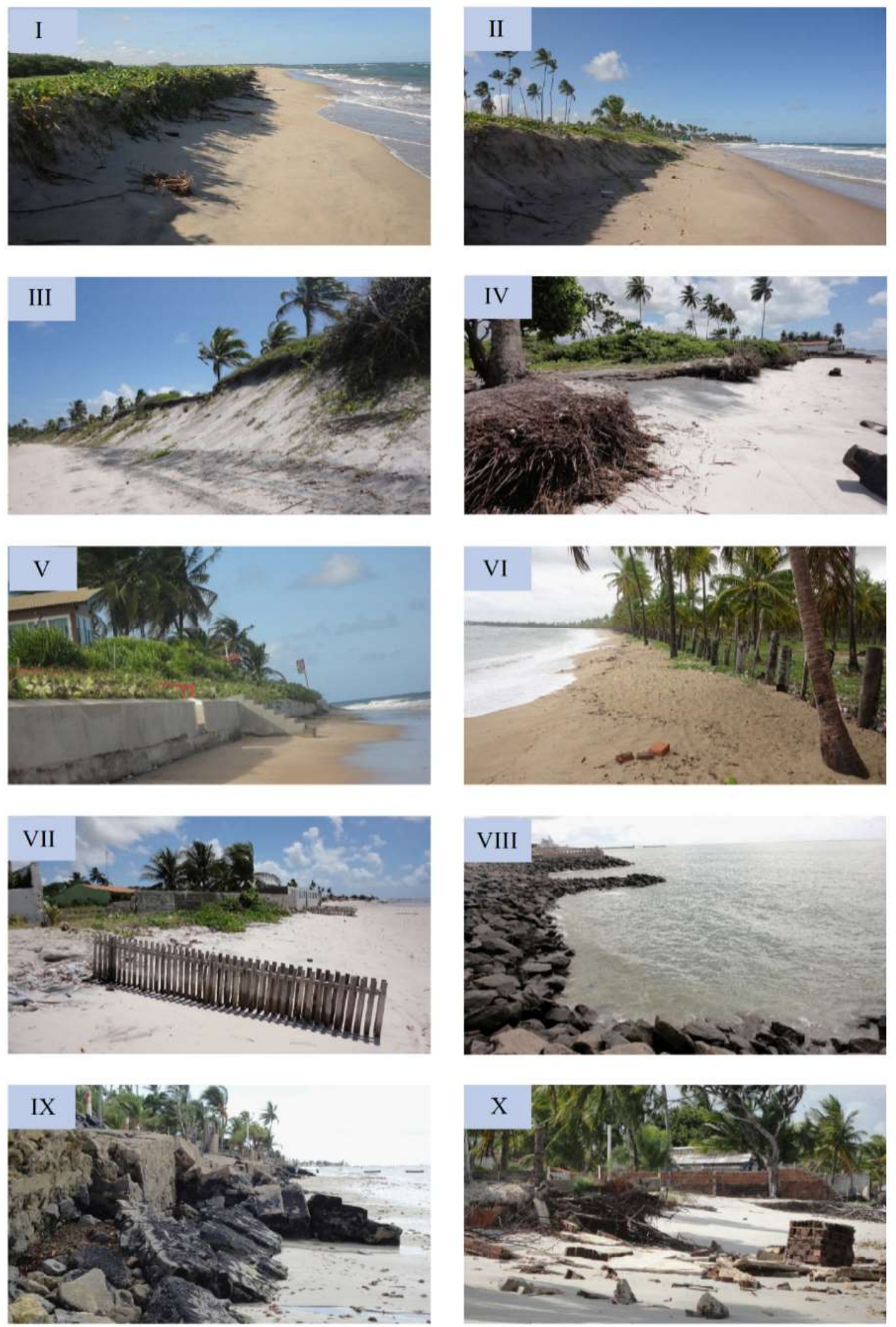

Figura 2 - Exemplo dos indicadores utilizados para definir o grau dos impactos de erosão costeira em Pernambuco (ver Tabela 1): I- Praia de Mamucabas (Ipojuca), II - Praia do Cupe (Ipojuca), III - Praia de Gamboa (Ipojuca), IV Praia de Catuama (Goiana), V- Praia do Cupe (Ipojuca); VI - Praia de Serrambi (Ipojuca), VII - Praia de Ponta de Pedras (Ipojuca); VIII - Praia do Farol (Olinda), IX - Praia de Catuama (Goiana), X-Praia de Enseada dos Golfinhos (Itamaracá). (Fotos dos autores, 2014). 
A LC de 2014 foi determinada em campo durante uma maré de sizígia equinocial, no mês de março de 2014. O trabalho de campo foi realizado em 10 dias durante as marés de sizígia do referido mês.

O método utilizado para definir a posição da LC de 2014 foi o limite entre a areia úmida e a areia seca ou a marca do limite superior da maré deixada por algas marinhas na praia. Em locais onde não foi possível identificar uma das marcas citadas, foi utilizado a base das dunas ou falésias, ou a primeira linha de vegetação ou de urbanização, como sendo o local de alcance máximo da maré.

Os $172 \mathrm{~km}$ de praias arenosas foram percorridos com um quadriciclo equipado com um aparelho de posicionamento global (GNSS - Global Navigation Satellite Systems) que realiza levantamentos geodésicos utilizando o sistema americano GPS (Global Positioning Systems) e o sistema russo GLONASS (Global Navigation Satellite System).

O GNSS operou em modo cinemático, coletando dados de latitude e longitude a cada 5 segundos, pelo método de pontos de posicionamento preciso, com precisão de $5 \mathrm{~cm}$. Posteriormente, os dados foram processados no software Leica GeoOffice ${ }^{\circledR}$, gerando um produto final no formato shape, com os dados georreferenciados em coordenadas UTM e datum SIRGAS 2000 zona $25 \mathrm{~S}$.

A variação da LC entre 2005 e 2014 foi estimada no software $A r c G i s{ }^{\circledR}$ por meio da criação de transectos perpendiculares à LC de 2005, com espaçamento de aproximadamente $1 \mathrm{~km}$ entre cada um deles, na mesma posição dos pontos de coleta dos geoindicadores de erosão. O comprimento dos transectos registrados na tabela de atributos define a magnitude da variação, sendo a retrogradação da $L C$ representada como valores negativos, enquanto a progradação é representada por valores positivos.

\section{Resultados e Discussão}

\section{Geoindicadores de erosão}

Os dez geoindicadores propostos na metodologia foram observados em campo (Tabela 1). Além desses, também foram encontrados outros possíveis geoindicadores de erosão tais como: exumação de arenitos de praia, leques de sobrelavagem e escarpa na berma formada durante a maré alta.

Tabela 1: Sumarização dos geoindicadores de erosão e o número de vezes detectado em campo.

\begin{tabular}{|c|c|c|}
\hline & Geoindicadores de erosão & $\begin{array}{l}\mathrm{n}^{\mathrm{o}} \text { de pontos } \\
\text { observados }\end{array}$ \\
\hline & Nenhum & 82 \\
\hline I & $\begin{array}{l}\text { Vegetação rasteira de duna ou restinga soterradas } \\
\text { ou com raízes expostas }\end{array}$ & 23 \\
\hline II & Escarpa erosiva nas dunas & 42 \\
\hline III & Concentração de minerais pesados na face da praia & 18 \\
\hline IV & Árvores na face de praia ou com raízes expostas & 38 \\
\hline $\mathrm{V}$ & Marcas de erosão na base de muros residenciais & 11 \\
\hline VI & Pós-praia estreito ou inexistente & 44 \\
\hline VII & Obras não estruturais de proteção costeira & 8 \\
\hline VIII & Obras estruturais de proteção costeira & 40 \\
\hline IX & $\begin{array}{l}\text { Infraestrutura da orla danificada pela energia das } \\
\text { ondas }\end{array}$ & 6 \\
\hline $\mathrm{X}$ & $\begin{array}{l}\text { Restos de construção na face de praia (ex.: pedaços } \\
\text { de ferro, tijolo, telhas) }\end{array}$ & 13 \\
\hline
\end{tabular}


Os geoindicadores: pós-praia estreito ou inexistente, escarpa erosiva nas dunas, obras estruturais de proteção costeira, e árvores na face de praia ou com raízes expostas foram os quatro geoindicadores observados com maior frequência ao longo do litoral de Pernambuco.

A alta frequência do "pós-praia estreito ou inexistente" é consequência de fatores antrópicos e naturais, sendo o primeiro causado por alterações do perfil de praia por construções próximas da LC, que alteram e confinam a dinâmica praial à uma estreita faixa de areia. Quanto aos fatores naturais podem ser citados o retrocesso da LC em decorrência do aumento do nível do mar como já foi descrito por Nicholls (2003) além da morfologia predominante das praias de Pernambuco. Essas são dominadas ou modificadas pela maré, o que sugere a ocorrência de um padrão refletivo durante a preamar e outro mais dissipativo na baixamar (MALLMANN et al., 2014). Este padrão corresponde com o que foi observado em campo, onde o limite máximo das ondas de preamar apresenta um padrão morfológico refletivo, seguido imediatamente por um terreno de baixo relevo com vegetação rasteira e coqueiros, sem a presença de pós-praia e dunas, caracterizando, nestes casos, um estágio morfológico e não necessariamente um geoindicador de erosão.

O segundo geoindicador mais observado foi a "escarpa erosiva nas dunas", onde a altura da escarpa variou desde poucos centímetros até mais de dois metros. As dunas escarpadas foram encontradas principalmente em áreas não urbanizadas, onde o perfil de praia foi preservado mesmo que sob efeito de um possível processo erosivo.

A presença de "obras de proteção costeira" como quebra-mar, espigão, muro e enrocamento foi o terceiro geoindicador mais observado. Grande parte destas obras são pontuais, executadas pelos proprietários de imóveis que veem seu patrimônio em risco e tentam protegê-lo, contudo há também grandes obras financiadas pelo poder público, sendo estas localizadas principalmente no Núcleo Metropolitano.

O quarto, foi a presença de "árvores na face de praia ou com raízes expostas", por exemplo os arbustos, árvores de mangue e coqueiros localizadas abaixo da linha de maré. Um dos motivos da alta frequência deste geoindicador é, também, consequência do estágio morfodinâmico dominante das praias de Pernambuco, que é marcado pela presença de vegetação muito próxima do limite máximo de preamar.

A análise estatística dos componentes principais mostrou que não existe uma correlação significativa entre os dez geoindicadores analisados, ou seja nenhuma acima de $80 \%$. Entretanto os resultados mostram uma boa correlação entre "árvores na face de praia ou com raízes expostas" e "escarpa erosiva nas dunas" de $67 \%$. Entre o "pós-praia estreito ou inexistente" e "obras estruturais de proteção costeira" foi encontrado uma correlação de $56 \%$. Esse resultado indica que além do alto impacto visual causado por este tipo de obra, parte das praias que foram protegidas com obras rígidas também perderam a função de recreação, uma vez que durante a maré alta não existe uma faixa de areia emersa para os usuários. Outro fator que leva a correlação entre estes dois geoindicadores é uma possível alteração da deriva litorânea gerada pela presença das obras de proteção, que resulta na geração de processos erosivos em praias adjacentes (PHILLIPS; JONES, 2006).

Sousa; Siegle e Tessler (2012) utilizando uma metodologia e uma seleção de indicadores semelhante a do presente estudo definiram um método para avaliar a vulnerabilidade do litoral. Os indicadores utilizados pelos autores citados acima foram: morfologia praial, exposição às ondas, configuração do campo de dunas, presença de rios ou inlets, elevação do terreno, tipo de vegetação, estruturas de engenharia costeira, grau de ocupação antrópica e permeabilidade do solo. Os autores concluíram que a análise de tais indicadores para calcular a vulnerabilidade do litoral é eficiente tanto para pequenas e grandes áreas.

\section{Classificação dos geoindicadores}

Os resultados dos geoindicadores de erosão foram agrupados em três classes de intensidade e mais uma contendo os segmentos de praia que não apresentaram nenhum dos geoindicadores analisados (Figura 3). Em 48\% (83 km) do litoral de Pernambuco não foram identificados geoindicadores de erosão. Outros 8\% (14 $\mathrm{km}$ ) apresentaram geoindicadores classificados como de baixa intensidade, $16 \%(28 \mathrm{~km})$ apresentaram geoindicadores de moderada intensidade e os demais $28 \%$ (47 $\mathrm{km})$ apresentaram geoindicadores de alta intensidade de erosão. 
a) Setor Norte

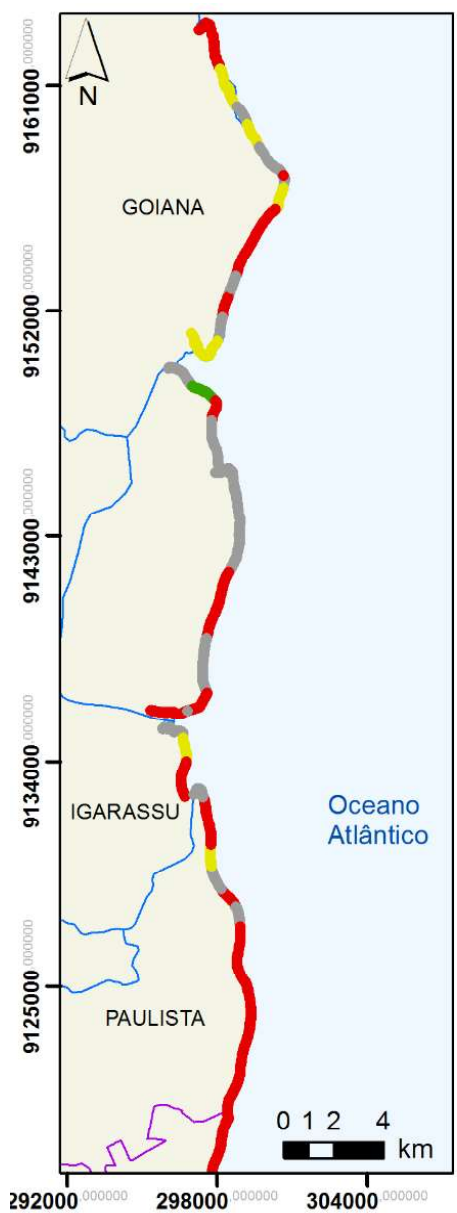

b) Núcleo Metropolitano

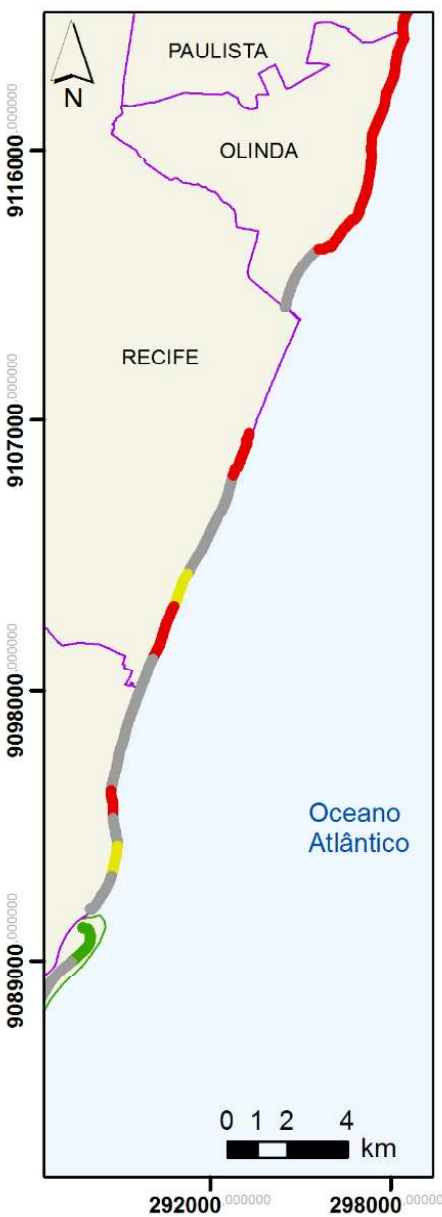

c) Setor Sul

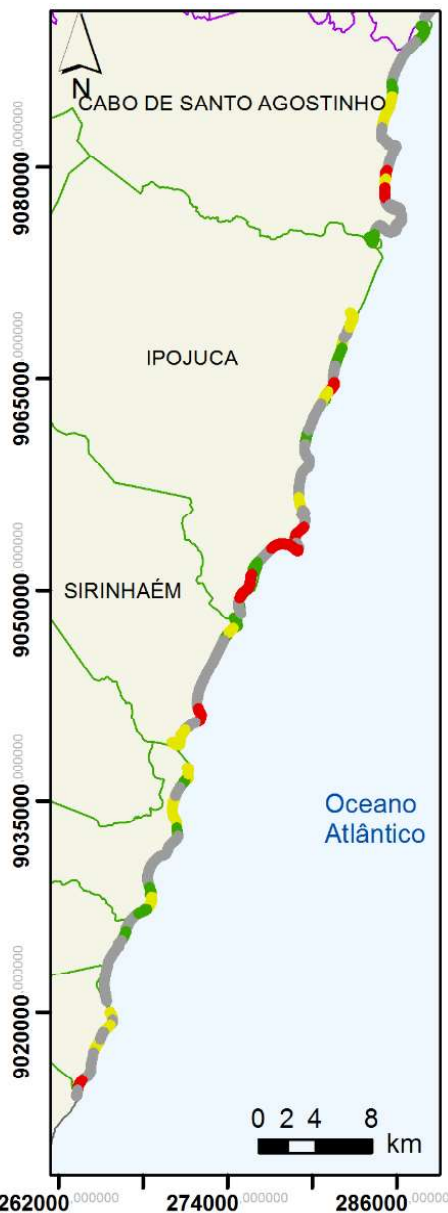

Geoindicadores de erosão

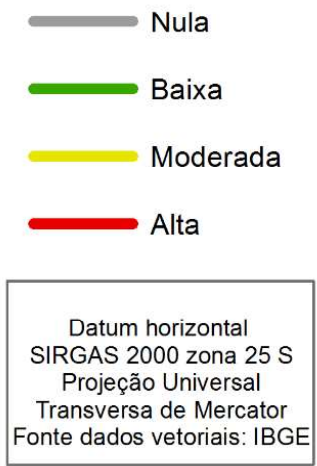

Figura 3 - Mapa de intensidade de impacto visual de erosão no litoral de Pernambuco. a) Setor Norte, b) Núcleo Metropolitano, c) Setor Sul.

O Setor Norte apresentou os resultados mais negativos entre os três setores (Figura 3a). Este apresentou 36\% (19 km) do litoral sem geoindicadores de erosão, distribuídos ao longo dos quatro municípios, principalmente no litoral da Ilha de Itamaracá e próximo da desembocadura dos rios que cortam este setor. Este resultado pode ser explicado pelo fato de que a foz de rios é um local de deposição de sedimentos, o que geralmente caracteriza processos de acreção nas praias adjacentes às margens destes (WRIGHT; THOM; HIGGINS, 1980).

Outros 2\% (1 km) foram classificados como baixa intensidade de erosão, localizados em três pontos no norte de Itamaracá. Nessa região há pouca ou nenhuma alteração antrópica e como a metodologia destaca os efeitos do processo erosivo na infraestrutura, as áreas menos urbanizadas sempre terão intensidade de erosão mais baixa. $14 \%(8 \mathrm{~km})$ do Setor Norte apresentou intensidade moderada, localizados em pontos isolados ao longo do mesmo.

Os demais $48 \%(25 \mathrm{~km})$ das praias apresentaram geoindicadores de alta intensidade de erosão, localizadas principalmente nos municípios de Goiana e Paulista. O município de Goiana possui diversos tipos de obra de proteção costeira, algumas obras rígidas, como muros de concreto e enrocamentos, e algumas obras de estruturas mais simples como espigões feitos de troncos de coqueiros, muros com sacos de areia, e armadilhas para fixar areia transportada pelo vento. Essas obras poderiam ser eficazes, entretanto a forma como foram construídas, com dimensões e espaçamento inapropriados, além da falta de manutenção inviabilizaram a contenção da erosão, como foi observado em campo. O município de Paulista possui intervenções antrópicas em toda a orla, 
com espigões, quebra-mares, enrocamentos e muros de concreto. As obras realizadas em Paulista garantem a proteção da infraestrutura da cidade, entretanto não conservam a praia, que é comprovado pela ausência de pós-praia ao longo de todo o litoral desse município. $\mathrm{Na}$ área com quebra-mares a circulação da água também foi alterada propiciando o desenvolvimento de tômbolos permanentes e não permanentes (PEREIRA et al., 2003).

No Núcleo Metropolitano os resultados são mais negativos do que a média do estado (Figura 3b). Este apresentou 44\% (12 km) do litoral sem nenhum dos geoindicadores analisados. Estas praias estão localizadas na Praia Del Chifre no município de Olinda que é uma região pouco habitada e bem conservada. Também não foram encontrados geoindicadores em trechos das praias do Pina e Boa Viagem em Recife, e na Praia de Piedade em Jaboatão dos Guararapes, que segundo o IBGE (2010) é a área com a maior densidade populacional do estado. Contudo, apresentam uma praia larga, com árvores e dunas vegetadas em alguns trechos. Isso demonstra que essas praias possuem um manejo adequado, que proíbe a destruição das dunas e remoção da vegetação, bem como qualquer tipo de construções na praia (RECIFE, 1996). O mesmo foi concluído por Costa et al. (2008) que classificou esta área como uma praia de boa qualidade sócio ambiental. Outro fator que favorece essas praias é o comportamento de acreção natural observado entre os anos de 2009 e 2012 em alguns trechos da Praia de Boa Viagem (MENDONÇA et al., 2014).

Outros $8 \%(2 \mathrm{~km})$ do Núcleo Metropolitano apresentaram intensidade moderada de erosão. Dentre estes está um trecho da Praia de Piedade que foi assim classificado por ser uma praia engordada (obra de proteção costeira não estrutural) e não apresentar nenhum dos demais geoindicadores analisados.

Os demais 46\% $(13 \mathrm{~km})$ do litoral do Núcleo Metropolitano tem intensidade alta de erosão. A maior parte da orla do município de Olinda não possui pós-praia mesmo na maré baixa e é fixada por enrocamento, além de possuir uma sucessão de 38 espigões curtos (MANSO et al., 2006). Pereira et al., (2003) realizaram uma pesquisa sobre a percepção dos usuários de algumas praias de Olinda e concluíram que as praias não são atrativas devido ao impacto visual das obras de proteção e a baixa qualidade da água. Alguns trechos de Recife e Jaboatão dos Guararapes também apresentam intensidade alta de erosão, como resultado da presença de enrocamentos e ausência de pós-praia no trecho sul de Recife, e quebra-mares no segundo município.

O Setor Sul caracteriza-se como o mais positivo em relação à média do estado (Figura 3c). Neste 56\% $(51 \mathrm{~km})$ das praias não apresentaram nenhum geoindicador de erosão, localizadas ao longo de todo o Setor Sul em áreas com pouca ou nenhuma urbanização. Com estas mesmas características outros 13\% (12 km) do litoral apresentaram intensidade baixa de erosão.

Cerca de 20\% (18 km) das praias apresentaram intensidade moderada, que estão localizadas ao longo de todo o Setor Sul. A urbanização nestes locais é composta principalmente por casas residenciais e pequenos comércios. O principal geoindicador observado nessas praias é a presença de árvores na face de praia ou com raízes expostas, além de escarpa erosiva nas dunas. Mallmann e Araújo (2010) analisaram a vulnerabilidade do litoral sul de Pernambuco e encontraram resultados semelhantes nesta região e constataram que houve retrogradação da LC no município de Tamandaré entre os anos de 1961 e 2006, que justifica a presença dos geoindicadores.

Os demais $11 \%(10 \mathrm{~km})$ do litoral compreendem as praias com intensidade alta de erosão, que estão localizadas principalmente na parte sul de Ipojuca. Estas possuem obras de proteção costeira, sendo que algumas já estão danificadas, além da ausência do pós-praia. No município de Cabo de Santo Agostinho, na Praia Enseada dos Corais, alguns trechos também não apresentam pós-praia emerso e os muros de contenção construídos para proteger casas se encontram danificados. A Praia de Enseada dos Corais possui formações recentes de arenito na face da praia, o que pode ter intensificado o processo erosivo como já descrito por Vousdoukas, Velegrakis e Plomaritis (2007).

Em 2006 o Ministério do Meio Ambiente publicou um estudo sobre a situação da erosão costeira no estado de Pernambuco, analisando 24 praias ao longo do litoral. Estas praias foram classificadas com grau de erosão moderada e alta, utilizando dados de variação de LC, danos a estruturas antrópicas, presença de obras de proteção, escarpa erosiva na base das dunas e exposição de arenitos na face de praia. A conclusão foi que cerca de $1 / 3$ das praias apresentavam erosão, decorrente de diversas causas, de caráter natural e antrópico, sendo que os autores consideraram as interações antrópicas o 
fator mais atuante na medida em que acelera processo erosivo, impedindo as praias de atingir o balanço sedimentar (MANSO et al., 2006).

Apesar da diferença metodológica, os resultados do estudo de 2006 foram semelhantes aos resultados do presente estudo. O local que mais apresentou mudanças foi o litoral do município de Goiana com a intensidade de erosão atual mais alta do que a determinada por Manso et al. (2006). Outra diferença constatada foi nas praias de Piedade e Boa Viagem no Núcleo Metropolitano, que no atual estudo apresentam baixa intensidade de erosão enquanto que em 2006 apresentava erosão alta. Isso pode ser em decorrência da acreção natural (SILVA et al., 2013) e de obras de engordamento realizadas na Praia de Piedade.

De acordo com Cutter; Boruff e Shirley (2003) o uso de indicadores relacionados à ocupação humana, em análises de perigos ambientais, geralmente leva à resultados mais preocupantes. $\mathrm{O}$ mesmo foi constatado por Mallmann e Araújo (2010) que a partir da análise da vulnerabilidade do litoral sul de Pernambuco, concluiu que os indicadores antrópicos exercem uma forte influência no resultado final da vulnerabilidade. Da mesma forma, no presente estudo as áreas com maior influência antrópica resultaram ser os de maior intensidade de erosão.

Um dado preocupante com relação aos geoindicadores de erosão observados no litoral de Pernambuco é o número de obras estruturais de proteção costeira realizadas de forma individual, pelos proprietários de imóveis. É evidente que muitas dessas obras foram realizadas sem a orientação adequada de um especialista em engenharia costeira, aumentando, com isso, as chances de fracasso da obra, além da possibilidade de intensificar o processo erosivo no local, ou transferi-lo pra as áreas adjacentes (VAN RIJN, 2011).

A presença de geoindicadores de erosão podem tornar as praias menos atrativa para o turismo, principalmente aquelas com a presença de obras estruturais de proteção costeira (ANFUSO et al., 2014). Nestas áreas, além da diminuição do turismo, as propriedades são desvalorizadas e consequentemente o comércio local é prejudicado. Em vista disso em regiões onde a economia é baseada na renda proveniente do turismo, as técnicas de manejo deveriam prezar a conservação da paisagem natural, utilizando métodos de proteção não estruturais como por exemplo a reconstrução de dunas e o engordamento de praia (ARIZA et al., 2014; BERRY; FAHEY; MEYERS, 2014; LOZOYAA; SARDÁA; JIMÉNEZ, 2014).

O método deste estudo pode ser comparado a outros amplamente utilizados como por exemplo Bush et al., (1999); Dal Cin e Simeoni (1994) e Gornitz; White e Cushman (1991), que apresentam um método simples que podem ser aplicado em diferentes escalas, e em áreas com escassez de dados de longo prazo.

\section{Variação da linha de costa}

Os resultados da variação da LC entre os anos de 2005 e 2014 mostram que nas praias de Pernambuco houve progradação, retrogradação e também situações de praias em equilíbrio. Os valores extremos de variação da LC no intervalo de tempo analisado foram de $200 \mathrm{~m}$ de progradação na Praia de Maria Farinha no município de Paulista e de $30 \mathrm{~m}$ de retrogradação na Praia de Ponta de Pedra no município de Goiana. A figura 4 mostra um mapa com os resultados da variação da LC separados em três classes, sendo a primeira de praias com retrogradação entre $-30 \mathrm{~m}$ e $-1 \mathrm{~m}$; a segunda representa as praias com a LC em equilíbrio com variações entre -1 e 10 m; e a terceira classe representa praias com progradação entre 10 e $200 \mathrm{~m}$.

As maiores taxas de erosão estão localizadas no extremo norte e sul do estado. Por exemplo a Praia de Ponta de Pedras, no município de Goiana, perdeu cerca de $30 \mathrm{~m}$ e a Praia da Várzea do Una, no município de São José da Coroa Grande, perdeu $25 \mathrm{~m}$. Esses dois exemplos são de praias afastadas de centros urbanos ou industriais, permitindo concluir que o processo erosivo existente nessas duas regiões está associado, principalmente, a fatores naturais.

As praias progradantes estão distribuídas ao longo de todo o litoral, principalmente em áreas próximas a desembocadura de rios. Como por exemplo a Praia de Maria Farinha no município de Paulista, localizada na margem esquerda do Rio Timbó que progradou cerca de 200 metros em direção ao mar, também a Praia de Mamucabas, localizada na margem direita do Rio Mamucabas no município de Barreiros, progradou cerca de 110 metros. Já a Praia de Piedade no município de Jaboatão dos Guararapes é um exemplo de progradação artificial, após uma obra de engordamento realizada em 2014 a Praia de Piedade progradou cerca de $70 \mathrm{~m}$ em direção ao mar. 
a) Setor Norte

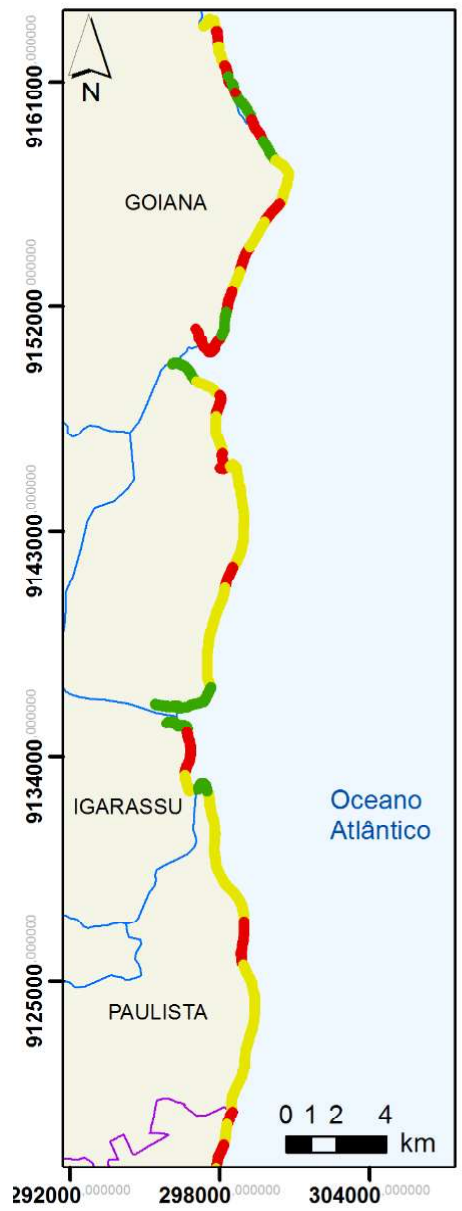

b) Núcleo Metropolitano

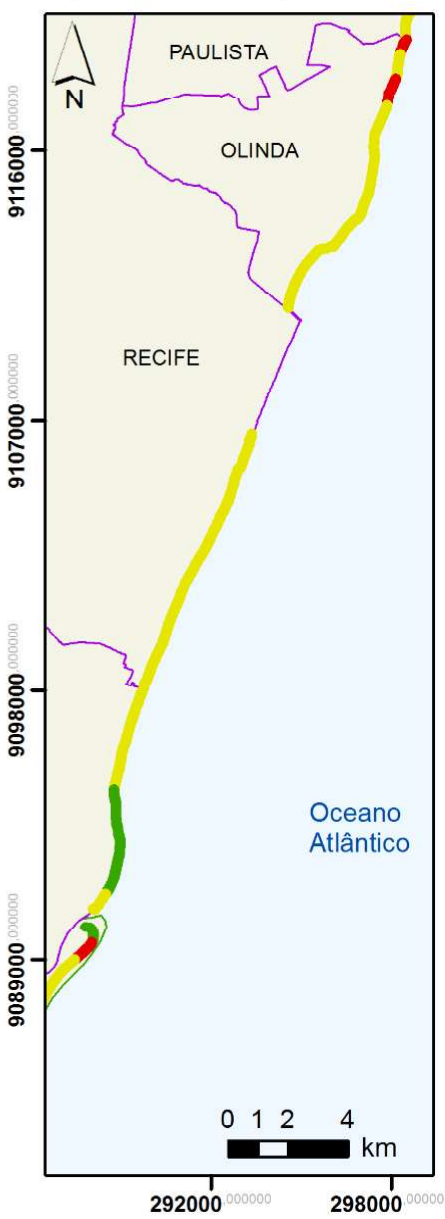

c) Setor Sul

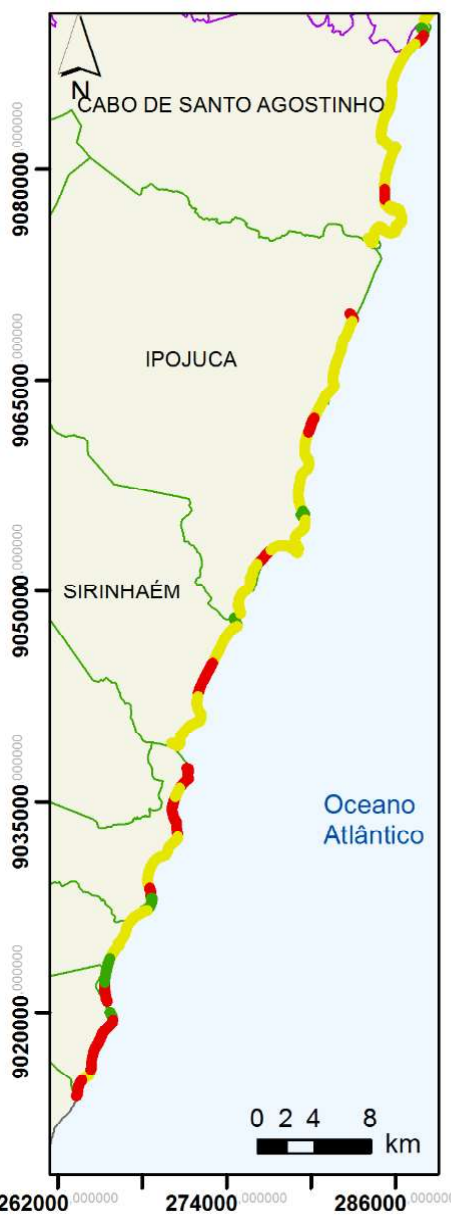

Variação da Linha de Costa

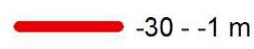

$-0,9-10 m$

10,1-200 m

Datum horizontal SIRGAS 2000 zona 25 S

Projeção Universal Transversa de Mercator Fonte dados vetoriais: IBGE

Figura 4 - Mapa das taxas de variação da linha de costa no litoral de Pernambuco. a) Setor Norte, b) Núcleo Metropolitano, c) Setor Sul.

Contudo, a maior parte do litoral pernambucano apresenta uma situação equilibrada da LC nos últimos 9 anos. Entretanto em alguns locais esse equilíbrio é mantido em virtude da fixação da LC com obras estruturais realizadas antes de 2009. Um exemplo é o Núcleo Metropolitano que tem um longo histórico de erosão, principalmente na orla do município de Olinda (NEVES; MUEHE, 1995) e a partir da década de 90 teve um crescimento do número de obras de proteção construídas ao longo do Núcleo Metropolitano com o intuito de reduzir a erosão (ARAÚJO; COSTA, 2009). Essa situação, em parte, explica a baixa correlação estatística entre a intensidade dos geoindicadores de erosão e a variação da LC, que foi de $15 \%$.

Em 2009 o estudo "Monitoramento Ambiental Integrado da Região Metropolitana do Recife " avaliou a vulnerabilidade costeira e constatou que, em algumas situações, locais com alta taxa de vulnerabilidade a LC era estável ou progradante. Isso foi explicado pelos autores por meio de uma variável denominada "deslocamento da linha de urbanização", que mostra que muitos problemas de erosão são causados pelo avanço da urbanização em direção ao mar e não do mar em direção ao continente (MALLMANN; PONTES; ARAÚJO, 2009).

Em contrapartida, no presente estudo, algumas praias com taxas de retrogradação da LC não apresentaram geoindicadores de erosão de alta intensidade. Essa situação ocorre principalmente no Setor Sul, em praias não urbanizadas, que sem a barreira física exercida pelas construções permite que os ambientes migrem naturalmente em direção ao continente, não apresentando assim os problemas decorrentes da erosão costeira.

Mallmann; Araújo e Droguett (2014) realizaram analises da variação da LC no Núcleo Metropolitano e obtiveram resultados semelhantes aos do presente estudo e concluíram que, embora não haja um estudo 
científico que mostre as causas da erosão com base na análise temporal de dados, é possível que as mesmas resultem da interação de distintos agentes naturais e antrópicos.

É importante monitorar a evolução da linha de costa uma vez que este é um instrumento fundamental para elaborar planos de gestão costeira que visem diminuir prejuízos às comunidades que vivem próximo da zona costeira (COOPER; PILKEY, 2004).

\section{Conclusão}

Os geoindicadores de erosão presentes em maior número na zona costeira de Pernambuco foram o pós-praia estreito ou inexistente; escarpa erosiva nas dunas; obras estruturais de proteção costeira; e árvores na face de praia ou com raízes expostas. Em $48 \%$ do litoral pernambucano não foram encontradas geoindicadores de erosão, enquanto os demais $52 \%$ apresentaram pelo menos um dos geoindicadores analisados.

O Setor Norte apresentou os resultados mais negativos entre os três setores, esta foi a região que apresentou a maior frequência de pequenas obras estruturais de proteção costeira. Os resultados do Núcleo Metropolitano foram semelhantes à média do estado, entretanto foi o setor que apresentou a maior porcentagem do litoral com geoindicadores de alta intensidade de erosão. O Setor Sul apresentou os resultados mais positivos, uma vez que as cidades desse setor têm uma menor densidade demográfica em relação aos outros setores da zona costeira de Pernambuco e, portanto, o setor com menos alterações antrópicas na orla.

O levantamento da LC de 2014 usando o método cinemático GNSS produziu dados consistentes que podem ser utilizados como referência para futuras pesquisas de análises temporais. Como a metodologia dos geoindicadores de erosão está intimamente relacionada com as interações antrópicas na zona costeira, não foi possível traçar uma relação entre a presença dos geoindicadores e a variação da LC.

Os resultados deste estudo permitem definir quais as áreas que podem estar sofrendo maior impacto negativo na economia em decorrência da diminuição do turismo, custos com obras de proteção, danos na infraestrutura e desvalorização da área. Tais dados podem servir como subsídio para elaborar planos de gestão costeira para os municípios.

\section{Agradecimentos}

Este projeto foi financiado pelo Fundo Nacional sobre Mudança do Clima do Ministério do Meio Ambiente e realizado pelo Departamento de Oceanografia em colaboração com o Departamento de Engenharia Cartográfica da Universidade Federal de Pernambuco, com a Secretaria de Meio Ambiente e Sustentabilidade de Pernambuco e com a Agência Estadual de Meio Ambiente de Pernambuco. Adicionalmente, os autores K. Martins e A. Lino gostariam de agradecer a CAPES pela concessão das bolsas de mestrado.

\section{Referências Bibliográficas}

ANFUSO, G.; WILLIAMS, A. T.; CABRERA HERNANDEZ, J. A.; PRANZINI, E. Coastal scenic assessment and tourism management in western Cuba. Tourism Management, v. 42, p. 307-320, jun. 2014.

ARAÚJO, T.; COSTA, M. Breve Histórico da Erosão na RMR. In: Monitoramento Ambiental Integrado - MAI. Recife: Universidade Federal de Pernambuco e Financiadora de Estudos e Projetos, 2009. v. 1, p. 26-30.

ARIZA, E.; LINDEMAN, K. C.; MOZUMBER, P.; SUMAN, D. O. Beach management in Florida: Assessing stakeholder perceptions on governance. Ocean and Coastal Management, v. 96, p. 82-93, ago. 2014.

BERRY, A. J.; FAHEY, S.; MEYERS, N. Boulderdash and beachwalls - The erosion of sandy beach ecosystem resilience. Ocean and Coastal Management, v. 96, p. 104-111, ago. 2014.

BRASIL. Decreto-lei $\mathrm{n}^{\circ}$ 5.300, de 07 de dezembro de 2004. Regulamentação da lei $n^{\circ} 7.661$, Plano Nacional de Gerenciamento Costeiro. Diário Oficial da República Federativa do Brasil, Poder Executivo, DF, 08/12/2004. Seção, p. 2.

BUSH, D. M.; NEAL, W. J.; YOUNG, R. S.; PILKEY, O. H. Utilization of geoindicators for rapid assessment of coastalhazard risk and mitigation. Ocean and Coastal Management, v. 42, n. 8, p. 647-670, ago. 1999.

COOPER, J. A. G.; PILKEY, O. H. Sea-level rise and shoreline retreat: Time to abandon the Bruun Rule. Global and Planetary Change, v. 43, p. 157-171, 2004.

COSTA, M. F.; ARAÚJO, A. C. B.; SILVA-CAVALCANTI, J. S.; SOUZA, S. T. Verticalização da Praia da Boa Viagem (Recife, Pernambuco) e suas Consequências Sócio-Ambientais. Revista da Gestão Costeira Integrada, v. 8, n. 2, p. 233-245, 2008. 
CUTTER, S. L.; BORUFF, B. J.; SHIRLEY, W. L. Social vulnerability to environmental hazards. Social Science Quarterly, v. 84, n. 2, p. 242-261, 2003.

DAL CIN, R.; SIMEONI, U. A model for determining the classification, vulnerability and risk in the southern coastal zone of the Marche, Italy. Journal of Coastal Research, v. 10, n. 1, p. 18-29, 1994.

DOMINGUEZ, J. M. L.; BITTENCOURT, A. C. S. P.; LEÃO, Z. M. A. N.; AZEVEDO, A. E. G. Geologia Do Quaternário Costeiro Do Estado De Pernambuco. Revista Brasileira de Geociências, v. 20, n. 1-4, p. 208-215, mar./dez.1990.

FERREIRA JÚNIOR, A. V.; ARAUJO, T. C. M.; VIEIRA, M. M.; NEUMANN, V. HJ.; GREGORIO, M. N. Petrologia dos arenitos de praia (beachroks) na costa central de Pernambuco. Geociências, São Paulo, v. 30, p. 545-559, 2011.

GORNITZ, V. M.; WHITE, T. W.; CUSHMAN, R. M. A Coastal Hazards Data Base for the U.S. East Coast. 7lh Symposium on Coastal \& Ocean Management, 174 p. EUA, 1991.

IBGE. Censo Demográfico 2010 - Resultados do universo. Disponível em: http://www.ibge.gov.br. Acesso em: 02 de fevereiro de 2015.

LOZOYAA, J. P.; SARDÁA, R.; JIMÉNEZ, J. A. Users expectations and the need for differential beach management frameworks along the Costa Brava: Urban vs. natural protected beaches. Land Use Policy Journal, v. 38, p. 397-414, maio 2014.

MALLMANN, D. L. B.; ARAÚJO, T. C. M. Vulnerabilidade Física do Litoral Sul de Pernambuco à Erosão. Tropical Oceanography, Recife, v. 38, n. 2, p. 130-152, 2010.

MALLMANN, D. L. B.; ARAÚJO, T. C. M.; DROGUETT, E. L. Caracterização do litoral central de Pernambuco (Brasil) quanto ao processo erosivo em curto e médio-termo. Quaternary and Environmental Geosciences, v. 05, n. 2, p. 137-154, 2014.

MALLMANN, D. L. B.; PEREIRA, P.; SANTOS, F.; FAÇANHA, P. Classificação morfodinâmica das praias arenosas de Ipojuca (Pernambuco, Brasil) através da análise semântica de imagens de satélite pancromáticas. Pesquisas em Geociências, Rio Grande do Sul, v. 41, n. 2, p. 169-189, maio/ago. 2014.

MALLMANN, D.; PONTES, P.; ARAÚJO, T. Vulnerabilidade. In: Monitoramento Ambiental Integrado - MAI. Recife, BR: v. 3, p. 12-82, 2009.

MANSO, V. A. V.; COUTINHO, P. N.; GUERRA, N. C.; SOARES JUNIOR, C. F. A. Pernambuco. In: MUEHE, D. (Org.). Erosão e Progradação do Litoral Brasileiro. Brasília, BR:
Ministério do Meio Ambiente, 2006. p. 179-196.

MENDONÇA, F. J. B.; GONÇALVES, R. M.; AWANGE, J.; SILVA, L. M. GREGORIO, M. N. Temporal Shoreline Series Analysis Using GNSS. Boletim de Ciências Geodésicas, Curitiba, v. 20, n. 3, p. 701-719, jul./set. 2014.

MINISTÉRIO DO TURISMO. Anuário Estatístico 2014 - Ano Base 2013. Disponível em: http://www.turismogov.br. Acesso em: 02 de fevereiro de 2015.

MUEHE, D. Erosão e progradação no litoral brasileiro. Brasília, BR: Ministério do Meio Ambiente - MMA, 2006. 476 p. ISBN 85-7738-028-9

NEVES, C. F.; MUEHE, D. Potential Impacts of Sea-Level Rise on the Metropolitan Region of Recife, Brazil. Journal of Coastal Research, v. SI 14, p. 116-131, 1995.

NICHOLLS, R. J. Case study on sea-level rise impacts. OECD Workshop on the Benefits of Climate Policy: Improving Information for Policy Makers, 2003. 32 p.

NICOLODI, J. L. Documento síntese do I Simpósio Nacional sobre Erosão Costeira. Brasília, BR: Ministério do Meio Ambiente - MMA, 2008. 25 p.

RECIFE. Lei $\mathrm{n}^{\circ}$ 16.176, de 9 de abril de 1996. Lei de Uso e Ocupação do Solo da Cidade do Recife. Plano Setorial de Uso e Ocupação do Solo, Prefeitura da cidade de Recife, 103 p.

PEREIRA, L. C. C.; JIMENEZ, J. A.; MEDEIROS, C.; COSTA, R. M. The influence of the environmental status of Casa Caiada and Rio Doce beaches (NE-Brazil) on beaches users. Ocean and Coastal Management, v. 46, n. 11-12, p. 1011-1030, 2003.

PHILLIPS, M. R.; JONES, A. L. Erosion and tourism infrastructure in the coastal zone: Problems, consequences and management. Tourism Management, v. 27, n. 3, p. 517-524, 2006.

PRASETYA, G. The role of coastal forests and trees in protecting against coastal erosion. In: BRAATZ, S.; FORTUNA, S.; BROADHEAD, J.; LESLIE, R. (Eds.). Coastal protection in the aftermath of the Indian Ocean tsunami: What role for forests and trees? Khao Lak, Thailand: Proceedings of the Regional Technical Workshop. p. 103-132, 2007.

RECIFE. Lei $\mathrm{n}^{\circ} 16.176$, de 9 de abril de 1996. Lei de Uso e Ocupação do Solo da Cidade do Recife. Plano Setorial de Uso e Ocupação do Solo, Prefeitura da cidade de Recife, 103 p. 1996.

SILVA, L. M.; GONÇALVES, R. M. G.; LIRA, M. M. S.; PEREIRA, P. S. Modelagem fuzzy aplicada na detecção da vulnerabilidade à erosão costeira. Boletim de Ciências 
Geodésicas, v. 19, n. 4, p. 746-764, 2013.

SOUSA, P. H. G. O.; SIEGLE, E.; TESSLER, M. G. Vulnerability assessment of Massaguaçú Beach (SE Brazil). Ocean and Coastal Management, v. 77, p. 24-30, 2012.

SOUZA, C. R. DE G. A Erosão nas Praias do Estado São Paulo: Causas, Conseqüências, Indicadores de Monitoramento e Risco. In: BONONI, V. L. R.; SANTOS JUNIOR, N. A. (Eds.). Memórias do Conselho Cientifico da Secretaria do Meio Ambiente: A Síntese de Um Ano de Conhecimento Acumulado. São Paulo, BR: Instituto de Botânica - Secretaria do Meio Ambiente do Estado de São Paulo, p. 48-69, 2009.
VAN RIJN, L. C. Coastal erosion and control. Ocean and Coastal Management, v. 54, n. 12, p. 867-887, 2011.

VOUSDOUKAS, M. I.; VELEGRAKIS, A. F.; PLOMARITIS, T. A. Beachrock occurrence, characteristics, formation mechanisms and impacts. Earth-Science Reviews, v. 85, n. 1-2, p. 23-46, 2007.

WRIGHT, L. D.; THOM, B. G.; HIGGINS, R. J. Wave influences on river-mouth depositional process: Examples from Australia and Papua New Guinea. Estuarine and Coastal Marine Science, v. 11, n. 3, p. 263-277, 1980. 